\title{
Working together more constructively towards open access
}

\author{
David Sweeney \\ HEFCE, Bristol, UK \\ E-mail:D.SWEENEY@hefce.ac.uk
}

\begin{abstract}
Open access is a key aim of research funders, institutions and academics. If sustainable solutions are to be found, we must work together as a whole community, including with publishers. Research funders have shown flexibility and sensitivity to publishers in how they make policies for delivering open access to the work they fund; for their part, publishers must now do their bit by acknowledging that a mixture of the green and gold routes is necessary to speed up any transition to open access, and by sorting out the perception problems associated with gold open access.
\end{abstract}

Keywords: Open access, publishing, scholarly communication, green, gold, double dipping, embargoes

Let me set out my view of how we can achieve open access. Before getting into the practical realities and challenges of delivering open access, I want to briefly reiterate my belief in open access to research, and set out the benefits it brings.

\section{Overarching aim: Widest possible dissemination}

My overarching belief is that research should be disseminated as widely as possible, for the benefit of all. The benefits that open access brings to the research community, to the economy and to wider society, are globally significant. Open access will allow for a more open and more efficient research process, allowing researchers more easily to create informed and informative material. It will allow businesses, charities and public sector organisations and governments to use the best and latest thinking to increase the positive impact they have on society. It will allow interested and talented individuals to learn more about the subjects that matter to them, and to access and interact with factual material directly.

All involved in the research process - researchers, universities, funders and governments - are in favour of opening up access to the fruits of research. Researchers are signed up to the principle, though they have noted some practical concerns. Universities are strongly in favour of open access, as it complements their mission to create strong economic and social benefits from their research. Funders all over the world are embracing open access as the way to deliver the maximum benefit and reach from the work they fund.

\section{Role of publishers}

It is in this context that I believe publishers of all kinds should play their part in opening up access to research. No matter what the delivery system is, and no matter how we get there, open access is the 
future. Many publishers I have talked to share this belief: making material broadly available is central to publishers' missions.

But for some players, open access is seen as a convenient opportunity to disturb and disrupt the current system of scholarly dissemination, with the aim of driving down costs and unleashing the full power of the Internet to drive the openness agenda through disorderly change. These people believe that anyone that stands in their way must be attacked. When faced with the prospect of real damage, publishers naturally take up defensive positions. We lose the opportunity to form constructive relationships and work toward innovative solutions together. In short, trying to break the system gets us nowhere.

\section{Working together}

I want to demonstrate that open access is possible by working together. We have a real opportunity to support each other in delivering wider and better access to research output, and to leave the bitter battles behind us.

The first thing to recognise is that changing the system of scholarly communication creates financial pressures. We know that higher education institutions are acutely aware of the financial risks of the transition to open access, particularly if the transition happens patchily across the globe. For publishers, too, the financial risks are substantial. I have therefore been strongly encouraged to see that publishers have been innovative in how they have embraced open access - imaginative publishers are offering realistic and workable open access options to authors and institutions. This includes the fee offsetting schemes provided by some publishers, and the wealth of green open access options provided by almost all publishers today. But publishers come in all shapes and sizes, from tiny print-only society publishers to complex multinational corporations. It is not for research funders to dictate how this ecology should change to meet the challenges of open access, but it is clear to me that if publishers are to survive the transition they must produce offerings that meet with the approval of the customer base.

\section{Balancing a preference for Gold OA with benefits of Green $\mathrm{OA}$}

As open access has gained in prominence over the last few years, two dominant models for achieving it have emerged: 'gold' and 'green'. 'Gold' refers to open access provided by publishers, 'green' by repositories. Because it represents a chance to improve the underlying economics of academic publishing by moving away from the subscription model, the UK government favours the gold method. But green open access has gained significant prominence too, and can be used in the immediate term to drive substantial increases in open access with low risk to publishers.

I believe it should be our long term aim to make open access work through the gold route, but not all in the research community agree with this today. There are two important questions to be answered if gold open access is to stand a chance of achieving widespread adoption.

The first question is this: does a mixed economy of gold and green models help with the transition to open access? We are currently testing out a stronger preference for gold in the UK. While the pots of money made available by the UK research councils and the Wellcome Trust to pay article processing charges are starting to be utilised, university libraries have told me that they cannot support a rapid push to gold open access unaided. Furthermore, models that emphasise that authors must pay to publish their work have frightened the academic community. It is for this reason that I believe that widespread open 
access is only possibly if gold and green are allowed to operate together, and researchers and libraries and given time to get used to the idea of open access and feel its benefits.

The second question is much thornier: how can we accelerate adoption of gold open access? Bound up with the question is a fundamental problem with gold - the problem of perception. People believe that gold open access brings increased costs to universities and researchers, and that publishers will exploit the push towards gold open access by supplementing their subscription income with article processing charges, rather than replacing it.

To publishers, the accusation of this sort of 'double-dipping' is an unfair one. Publishers argue that subscription levels, globally, have reduced substantially in recent years, and that it is not the fault of publishers that library budgets are strained. And they argue that the provision of open access through article processing charges and the provision of access through subscriptions are two different services. But to those in the research community, and particularly those at higher education institutions that produce a lot of research, these arguments do not ring true.

These challenges help to explain why gold open access is apparently happening so slowly. As long as perceptions of double-dipping remain, gold open access will be held back, perhaps indefinitely.

Turning to green open access, it is clear to me and many others that it provides a less attractive longterm option, not least because it relies on the continuation of the existing subscription model. However, we do know that most publishers support green open access, including the most prestigious houses, so there is real potential here for increasing the amount of material that is open access in the immediate term by following the green route.

When we look at the green open access policies of many publishers, though, we find that journals are asking authors to wait a year, sometimes two or three years, before the deposited article becomes open access. These delays have led some to argue that green open access with embargoes is not really open access at all: delaying access to the latest research diminishes its potential in much the same way that subscriptions do. It is the long term aim of HEFCE and other research funders to minimise these delays, and eventually eliminate them.

Publishers argue that these delays are necessary to protect their subscription incomes, but to me this does not ring true. Firstly, the subscription decisions of libraries are not based on the length of embargo periods - they are based on the value added by publishing: sifting and editing articles and presenting them in trusted venues. By asking for delays to the text of individual articles on the grounds that faster access to the raw text would lead people to cancel subscriptions, publishers underestimate the value they provide to the research process.

Secondly, I do not believe that there is a reliable link between the half-lives of journals and the subscription decisions of libraries. Here, only one example is needed: physics. Physics papers have very long half-lives, comparable to those in the humanities. But physicists have been uploading their papers to arXiv.org for years, often as the peer-reviewed text and without delay, and it has had no discernible impact on journal subscriptions. This is a living example of how green open access can work alongside journals that are supported by their subscribers.

\section{Publishers cooperating with the academic community}

In light of all of the above, the message I have for publishers is a simple one. If publishers want to join me in working together to drive forward open access, they must be willing to do two things. Firstly, they must be willing to test long-standing assumptions about green open access and its supposed 
effects on the subscription model. I have no wish to undermine publishers' businesses and make journals unsustainable, but publishers must be willing to accept that there is a strong and healthy role for green open access, at least in the short term.

Secondly, publishers must be willing to tackle the issue of the negative perceptions of gold open access, and specifically that publishers are exploiting gold open access as a means to increase their revenues by double-dipping.

If publishers can do these two things, then research funders can continue to argue for constructive approaches that support the current research dissemination ecology in making a smooth transition to open access. All players must be willing to do their bit to tackle these challenges constructively, because it is only by working together that we can deliver a realistic and sustainable open access future. 